\title{
Intrauterine growth restriction: Recent developments, definitions and future research
}

\author{
Roger A McMASTER-FAY* \\ Department of Obstetrics, Gynaecology and Neonatology, Central Clinical School, University of Sydney School of Medicine, Sydney, Australia
}

\begin{abstract}
The subject of intrauterine growth restriction has and continues to be in confusion because academic journals continue to publish articles that define the outcome of this disease as low birthweight or small for gestational age. This fault has been recently addressed with the recent publication of Fetal-Placental Growth Restriction: a series of 28 articles in 7 sections by 56 recognised authors. But even in this publication no alternative to low birthweight is clearly defined as an alternative to describe the outcome of this disease. As the name of this publication implies, this aberrant fetal growth has its origin in the maldevelopment of a normal, low resistance, uteroplacental circulation. It is therefore not surprising the many these cases have been detected preclinically using in mid-pregnancy uteroplacental Doppler flow studies.
\end{abstract}

Previous studies have shown that an improvement in outcome definition is achieved when it address the asymmetry of growth these infant have. This review concludes that a ratio of birthweight to head circumference would be the simplest and most appropriate definition.

\section{Introduction}

Many infants with a low birthweight (BWt) are healthy and many infants with a normal BWt have suffered with intrauterine growth restriction (IUGR) that puts them at increased risk of peri-partum morbidity and mortality [1,2]. The term Placental-Fetal Growth Restriction (PFGR) was recently conceived by the editors of the book of the same name [3]. These editors are cognisant of the inadequacy and hence the inaccuracy of the perception of small for gestational age (SGA) as describing clinically relevant IUGR. From our decades old works on asymmetrical IUGR [2,4], we endorse the theory and terminology of FPGR as the most relevant to this clinical entity. PFGR has its origin in uteroplacental insufficiency [3].

\section{Body of review}

It is over twenty five years since, we published our original study on asymmetrical versus symmetrical IUGR in a population of 2,500 consecutive births [2]. We found in term infants, Ponderal index (PI) to be a better measure of infants with intrauterine growth problems than birth-weight centiles with higher rates of Caesarean section delivery and fetal distress / stillbirths.

\section{$\mathrm{PI}=\mathrm{BWt}(\mathrm{g}) /[\text { Crown-heel length }]^{3} \mathrm{X} 100$}

In a similar study of 3,540 births, published just before ours, Villar et al. [1] showed that the highest rates of perinatal distress at term occurred in the subgroup with a normal birthweight but a low Ponderal index. They also found that the rates of perinatal distress were all higher in the low Ponderal index subgroups than in the low birthweight (SGA) subgroups (Figure 1). We subsequently went on to publish the review 'Categories of intrauterine growth retardation' [4].

In Placental-Fetal Growth Restriction [3] no alternative to SGA is put forward as an outcome definition of PFGR. The only oblique reference is: "a fetus growth restricted secondary to placental insufficiency is said

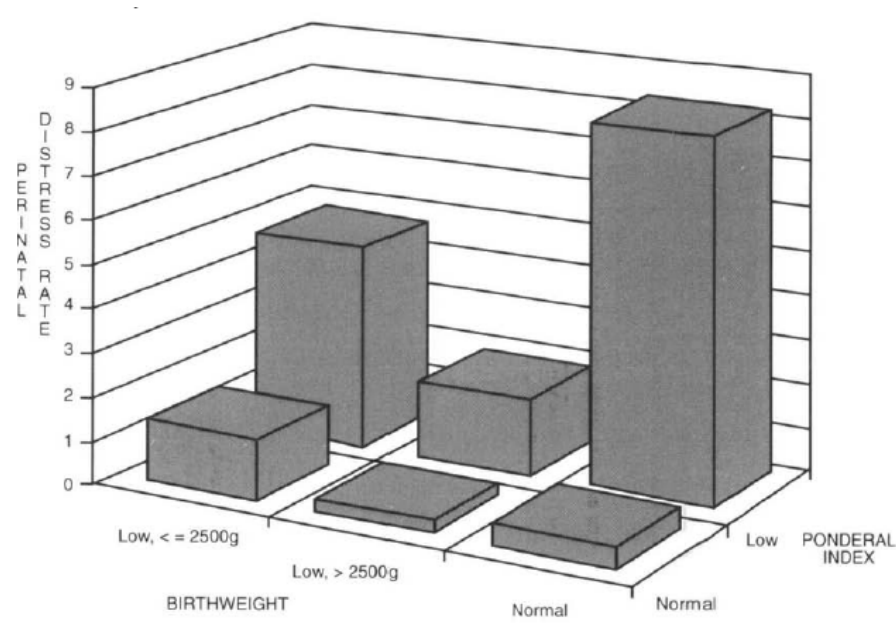

Figure 1. Perinatal distress rates in symmetric, asymmetric and normally grown infants (from data of Villar et al. [1])

to exhibit an asymmetrical pattern of growth restriction, but mixed patterns of fetal growth are possible. In very early FGR, symmetrical fetal growth is seen" [5].

We recently [6] were thus not surprised that Parry et al. [7] in their analysis of the data they collected in the Nulliparous Pregnancy Outcomes Study: Monitoring Mothers-to-be (nuMoM2b) [8], did not find second-trimester uterine artery Doppler studies to be a clinically useful test for predicting SGA babies.

${ }^{\star}$ Correspondence to: Roger A McMaster Fay, PO Box 82, Emu Plains, NSW 2750, Australia, Tel: +61 438354 900; E-mail: roger@rfay.com.au

Received: September 30, 2019; Accepted: October 15, 2019; Published: October 18,2019 
More recently, the ratio of BWt to head circumference has been propose as a measure of asymmetric growth retardation (AGR) $[9,10]$. Bocca-Tjeerets et al. [9], in a study of 810 preterm infants, defined AGR as any newborn infant with a BWt $z$-score more than 1SD than its corresponding $\mathrm{HC} z$-score. Using this formula $11 \%$ of in infants born between 35 and 32 weeks and $10 \%$ between 31 and 25 weeks gestation had AGR.

Goncalves et al. [10] used a BWt $/ \mathrm{HC}$ ratio of $\geq 0.9$ to disproportionate (asymmetric) fetal growth in a study of 915 term infants. They found these infants had other indicators of fetal wasting on measuring their chest circumference, arm circumference and triceps skinfold thickness.

We propose an analysis of the $n u M o M 2 b$ data to calculate the predictive ability of this BWt/HC ratio for PFGR [11].

[Despite the above publications [1,2,4] there has little if any academic comment, criticism or further studies of this or any other measures of this clinically relevant asymmetrical form of IUGR. Unfortunately, none of these publications are mentioned in PlacentalFetal Growth Restriction [3]]

[These FPGF infants are 'skinny' (look waisted) close to term because of vascular shunting away from fat, muscle and visceral tissue in favour of brain and heart - 'brain sparing. Further away from term, before the development of muscle and viscera and the laying down of fat, growth restriction is more general and hence the more symmetric (rather than the asymmetric).]

Uteroplacental vascular insufficiency is the cause of PFGR [3] and as such is one of the Uteroplacental Vascular Syndromes (UPVS) [11].

DeWolf et al. [12] found that the same vascular disease of the placental bed that is seen in pre-eclampsia occurring in pregnancies with IUGR without pre-eclampsia. Steel et al. [13] found that patients with an abnormal uterine artery Doppler flow velocity waveform at 24 weeks gestation had an increased risk of delivering an infant with asymmetrical IUGR. In our study of mid-trimester UA Doppler in predicting abnormal pregnancy outcome, we found that at 18 weeks the test performed poorly at predicting SGA alone but well at predicting asymmetrical IUGR.

With improved analysis of the uterine artery flow velocity waveforms, by combining the parameters of peak systolic and end diastolic flow with presence and depth of the early diastolic notch [14], it is thought that the test will become more sensitive. We again plan to test this hypothesis on the nuMoM2b data when it becomes available. This is data base of over 8,000 nulliparous pregnancies.

Thus, in more cases this vascular abnormality of a maldeveloped uteroplacental circulation should be detectable many months before the infant seriously suffers from the problem, in the mid-trimester.

\section{A measure of asymmetry of growth}

In adult medicine we have a widely used measure of asymmetry of growth in the Body Mass Index (BMI):

$$
\mathrm{BMI}=\mathrm{Wt}(\mathrm{kg}) / \text { Height }(\mathrm{m})^{2}
$$

Infant Ponderal Index is likewise a measure of weight for height:

$$
\mathrm{PI}=\mathrm{BWt}(\mathrm{g}) /[\text { Crown-heel length }]^{3} \mathrm{X} 100
$$

PI has been the probably the most commonly used measure of asymmetry of growth of infants and the measure that we used $[1,2,4]$.
So, both BMI and PI use length as the indicator of growth potential against which weight is the measure of growth attained.

Perhaps there is another infant biometric measure that is easier to obtain and probably a better measure of growth potential especially in regard to this 'brain sparing' $[4,9]$ form of IUGR. We suggest that in newborn infants a more reliable parameter of growth potential would be head circumference (HC) and we thus propose that an index of BWt ( $\mathrm{g}$ ) divided by $\mathrm{HC}(\mathrm{cm})$ be the measure of IUGR and it be called the Cephalic Index (CI).

$$
\mathrm{CI}=\text { Weight }(\mathrm{g}) / \mathrm{HC}(\mathrm{cm})
$$

Bocca-Tjeertes et al. [9] set a precedent for using BWt and head circumference for defining asymmetric growth restriction. They used it in the analysis of a population of preterm infants.

Goncalves et al. used BWt / HC ratio to be an important indicator of fetal growth. They found that these infants with a low BWt / HC also had other indicators of asymmetric growth restriction [10]. We plan to test the Cephalic Index on the nuMoM2b [7] infant population data.

\section{Conclusions}

SGA should no longer be seen as synonymous with IUGR. IUGR should now be replaced with FPGR. A new measurement of outcome for FPGR is urgently needed to replace SGA. A measure of asymmetry of growth would be best in the term and late preterm infants. FPGR is one of the uteroplacental vascular syndromes (UPVS) and more work on uteroplacental Doppler studies in mid-pregnancy needs to be done to further clarify its early detection.

With new large data bases becoming available, the above projects are now possible in the near future.

\section{References}

1. Villar J, de Onis M, Kestler E, Bolanos F, Cerezo R, et al. (1990) The differential neonatal morbidity of the intrauterine growth retardation syndrome. Am J Obstet Gynecol 163: 151-157.

2. Fay RA, Dey PL, Saadie CM, Buhl JA, Gebski VJ (1991) Ponderal Index: a better definition of the 'at risk' group with intrauterine growth problems than birthweight for gestational age in term infants. Aust N Z J Obstet Gynaecol 31: 17-19. [Crossref]

3. Lees C, Visser GHA, Hecher K (2018) Editors. Placental-Fetal Growth Restriction. Cambridge UK: Cambridge University Press.

4. Fay RA, Ellwood DA (1993) Categories of intrauterine growth retardation. Fetal Maternal Med Rev 5: 203-212.

5. Usman S, Lawin-O'Brien L, Lees C (2018) Differential diagnosis of fetal growth restriction. In: Placental-Fetal Growth Restriction. Cambridge UK: Cambridge University Press.

6. McMaster-Fay RA, Hyett JA (2018) Uterine artery Doppler studies in early second trimester to predict abnormal pregnancy outcome. Am J Obstet Gynecol 219: 418.

7. Parry S, Sciscione A, Haas DM, Grobman WA, Iams JD, et al. (2017) Role of early second-trimester uterine Doppler screening to predict small-for-gestational-age babies in nulliparous women. Am J Obst Gynecol 217: 1e1-8. [Crossref]

8. Haas DM, Parker CB, Wing DA, Parry S, Grobman WA, et al. (2015) A description of the methods of the Nulliparous Pregnancy Outcomes Study: monitoring mothers-to-be (nuMoM2b). Am J Obstet Gynecol 212: 539.e1-e24. [Crossref]

9. Bocca-Tjeertes I, Bos A, Kerstjens J, de Winter A, Reijneveld S (2014) Symmetrica and asymmetrical growth restriction in preterm-born children. Pediatrics 133: e650656. [Crossref]

10. Goncalves FC, de Lira PI, Eickmann SH, de Calvero Lima M (2015) Weight/head circumference ratio at birth for assessing fetal growth. Cadernos de Saude Publica 31: 1995-2004. [Crossref]

11. McMaster-Fay RA (2018) Uteroplacental vascular syndromes: Theories, hypothese and controversies. Clin Obstet Gynecol Reprod Med 4: 1-5. 
12. DeWolfe F, Brosens I, Ranaer M (1980) Fetal growth retardation and the maternal arterial supply of the human placenta in the absence of sustained hypertension. $\mathrm{Br} J$ Obstet Gynaecol 87: 678-685. [Crossref]

13. Steel SA, Pearce JM, McPharland P, Chamberlain GVP (1990) Early Doppler ultrasound screening in prediction of hypertensive disorders of pregnancy. Lancet 335 : 1548-1551. [Crossref]
14. Fay RA, Ellwood DA, Bruce S, Turner A (1994) Colour Doppler imaging of the uteroplacental circulation in the mid-trimester: features of the uterine artery flow velocity waveform that predict abnormal pregnancy outcome. Aust $N Z \mathrm{~J}$ Obstet Gynaecol 34: 515-519.

Copyright: (C2019 McMaster Fay RA. This is an open-access article distributed under the terms of the Creative Commons Attribution License, which permits unrestricted use, distribution, and reproduction in any medium, provided the original author and source are credited. 